\title{
Optimization of the process of electrochemical wastewater treatment of yeast production
}

\author{
Anna Poshtarenko, ${ }^{1, *}$ \\ ${ }^{1}$ National Aviation University, Department of Biotechnology, 1 Liubomyra Huzara ave., 03058, Kyiv, \\ Ukraine
}

\begin{abstract}
The process of purification and disinfection of yeast production sewage under the action of electrodialysis has been studied. As a result of research to determine the physicochemical and microbiological sewage composition, it was found that in sewage of the 1st degree of yeast separation has the highest excess content of organic and mineral substances in terms of: Chemical oxygen consumption (COC) - 31096/500 mg O2 / $\mathrm{dm} 3$, suspended solids - $6800 / 300 \mathrm{mg} / \mathrm{dm} 3$, chlorides $-2147 / 350 \mathrm{mg} /$ $\mathrm{dm} 3$ and sulfates $-6089 / 400 \mathrm{mg} / \mathrm{dm} 3$. The content of organic substances, which is characterized by the Chemical oxygen consumption (COC) indicator, in sewage of general discharge, $2 \mathrm{nd}$ and $3 \mathrm{rd}$ degree of yeast separation is $41 \%, 50 \%$ and $74 \%$ and that is lower than in sewage of the 1 st degree of yeast separation. The number of microorganisms in terms of Total microbial count (TMC) in sewage of the 1st stage of yeast separation is the largest and is 12.107 colony-forming units $\mathrm{CFU} / \mathrm{cm} 3$. It is determined that the process of sewage treatment and disinfection from minerals occurs more efficiently in the cathode zone, and from organic substances and microorganisms - in the anode zone of the electrodializer at a water temperature of $293 \mathrm{~K}$, current of $0.1 \mathrm{~A}$ and duration of exposure 20 $\min$.
\end{abstract}

\section{Introduction}

Water as the main or auxiliary raw material is used in the vast majority of food production technological processes. Almost all food production is associated with the consumption of tap water and groundwater aquifers [1].

The development of industrial production, in particular the food industry, increases the amount of waste that has a detrimental effect on the environment.

Food industry wastes are mainly disposed by technologies inherent in the utilization of solid household waste of the country housing and communal services.

Today, most municipal biological sewage treatment plants work extremely inefficiently, resulting in pollution of natural reservoirs, the processes of their flowering and overgrowth, etc. [2].

Industrial enterprises poison ponds with sewage, which contains a large amount of heavy metals, cyanides, etc. Domestic effluents and wastes of the food industry are

\footnotetext{
* orresponding author: strutinskaya@ukr.net
} 
especially harmful due to the fact that the oxidation of these substances in water bodies takes a lot of oxygen [3].

Modern water purification technologies (membrane, sorption, catalytic, etc.) allow to purify water from any pollution. However, the application of these methods increases the cost of purified water and does not always unambiguous consequences of its use. One of the areas that allow more rational organization of purification processes is the implementation of synthesis modern concepts of chemical-technological systems (CTS). Typical sewage treatment schemes include pre-treatment by physical (settling, filtration, flotation), physicochemical (coagulation) and biological (mostly aerobic) methods. [4].

A typical method of treatment of such sewage is biological. However, very often the limited area and location of enterprises near the estates do not allow from both technical and sanitary points of view to arrange biological sewage treatment. [5].

Therefore, the search for alternative means of disposal and effective wastewater treatment is relevant for the entire processing industry. Important arguments to solve these problems are increasing the requirements for the environmental condition of enterprises and the need to pay for waste disposal in accordance with current legislation of Ukraine [6].

The yeast industry, as well as other enterprises of the food industry, is tasked with developing rational methods of process water preparation and reducing the amount of industrial effluents. One of the promising ways to treat natural waters and industrial effluents is the method of electrodialysis.

There are many reports in the literature $[7,8,9,10,11,12,13]$ on similar experimental work on the treatment of natural and sewager using electric current, but the influence of a number of factors on the process of electrolytic treatment has not been studied enough. Preparation of water for the nutrient medium in accordance with the requirements of yeast production technology and a number treatment of specific industrial effluents of yeast plants (industrial waters of baker's yeast separation shops) has not been studied at all by this method.

Traditional water treatment technologies based on coagulation and settling, as well as oxidation or ion exchange are ineffective in the conditions of modern anthropogenic loads and new more stringent requirements for drinking and industrial water quality. The use of membrane technologies in industry opens wide prospects for the possibility of creating fundamentally new energy-saving, environmentally friendly technological schemes. [14]

Analysis of the literature has shown that among the many known electrochemical methods of sewage treatment are electrolysis in a diaphragm-free electrolyzer of a solution containing sodium chloride, which is added to sewage to oxidize bacterial contaminants [15]. The disadvantage of this method is that for electrolysis uses a solution of sodium chloride with a concentration of at least $150-200 \mathrm{mg} / \mathrm{dm} 3$, from which is formed and used about $10-15 \%$ of sodium hypochlorite. Another amount of salt is introduced into the water in the form of ballast ions, thereby increasing the overall mineralization of the aqueous phase, which is unfavorable for the environment and increases the cost of disinfection.

There is a method of electrochemical treatment of water with disinfectants by direct electrolysis, which consists in its flow through a diaphragmless cell with insoluble anodes, in which under the action of a direct electric current on the anodes flows chlorine ions with the release of chlorine gases and oxygen dissolving in water [16]. The disadvantage of this method is the significant energy consumption of the oxidation process. This is due to the fact that during the electrochemical treatment of water at the cathode hydrogen gas is released, which is a reducing agent and neutralizes part of the gaseous chlorine and oxygen as bacterial contaminants oxidants. In addition, this method requires the presence in the water of a certain minimum concentration of chlorides, below which the process of electrochemical disinfection becomes inefficient. 
There is a method of water purification, including the introduction of a coagulant containing aluminum hydroxide and treatment of water in a diaphragm-free cell using insoluble electrodes [17]. Electro-treatment of water with the use of insoluble electrodes, in which aluminum hydroxide is introduced as a coagulant, allows to improve its coagulating qualities, reduce the processing time and simplify the method of water purification. The disadvantage of this method is its low performance, as when using this method does not disinfect the water and requires further treatment with a disinfectant.

There is a method of electrochemical treatment of water with disinfectants by direct electrolysis, which consists in its flow through a diaphragmless cell with insoluble anodes, in which under the action of a direct electric current on the anodes flows chlorine ions with the release of chlorine gases and oxygen dissolving in water [18]. The disadvantage of this method is the significant energy consumption of the oxidation process. This is due to the fact that during the electrochemical treatment of water at the cathode, hydrogen gas is released, which is a reducing agent and neutralizes part of the gaseous chlorine and oxygen as oxidants of bacterial contaminants. In addition, this method requires the presence in the water of a certain minimum concentration of chlorides, below which the process of electrochemical disinfection becomes inefficient.

The disadvantage of electrodialysis is the inability to clean uncharged substances. However, for water treatment purposes in the yeast industry, this problem is less important because the incoming water usually contains a minimum amount of such substances, and the main problem is the presence of microorganisms, organic acids and various salts. This means that electrodialysis can be used for water treatment purposes in the yeast industry.

The use of electrodialysis is attractive because it requires minimal equipment. In addition, the proposed method has a number of technological advantages over known methods of electrochemical water disinfection, as there is no need for transportation and storage of hazardous reagents for oxidation of contaminants and $\mathrm{pH}$ adjustment of treated water, and simplifies maintenance of equipment and control of electrochemical water treatment. Changing the current to obtain the desired effect of disinfection. [19].

The purpose of the work is to determine the optimal parameters of the process of purification and disinfection of sewage of yeast production under the action of electrodialysis.

The task of the work is to build a mathematical model to obtain the optimal parameters of the process of sewage treatment and disinfection to minimize the amount of pollutants and microorganisms.

\section{Materials and methods}

\subsection{Preparation of sewage samples}

The sewage was poured under sterile conditions into pre-sterilized $200 \mathrm{ml}$ glass bottles.

\subsection{Conditions of sewage treatment in an electric dialyzer}

Sewage treatment and disinfection were performed in a laboratory electrodializer (Figure 1).

The electrolytic cell is a rectangular cuvette $60 \mathrm{~mm}$ wide, $250 \mathrm{~mm}$ high and long, which is made of plexiglass. In the middle part of the device the membrane (1) from fabric "belting" is established. The working surface makes $6,25 \mathrm{~m} 2$. In lateral parts of the device insoluble electrodes are established. The cathode (2) is made of a non-continuous titanium plate with a thickness of $1 \mathrm{~mm}$. The anode (3) is made of a solid plate with a thickness of 1 
$\mathrm{mm}$ and a working surface of $6.25 \mathrm{~m} 2$. of stainless steel. The distance between the cathode and the anode is $48 \mathrm{~mm}$. The usable volume of the device is $0.003 \mathrm{~m} 3$.

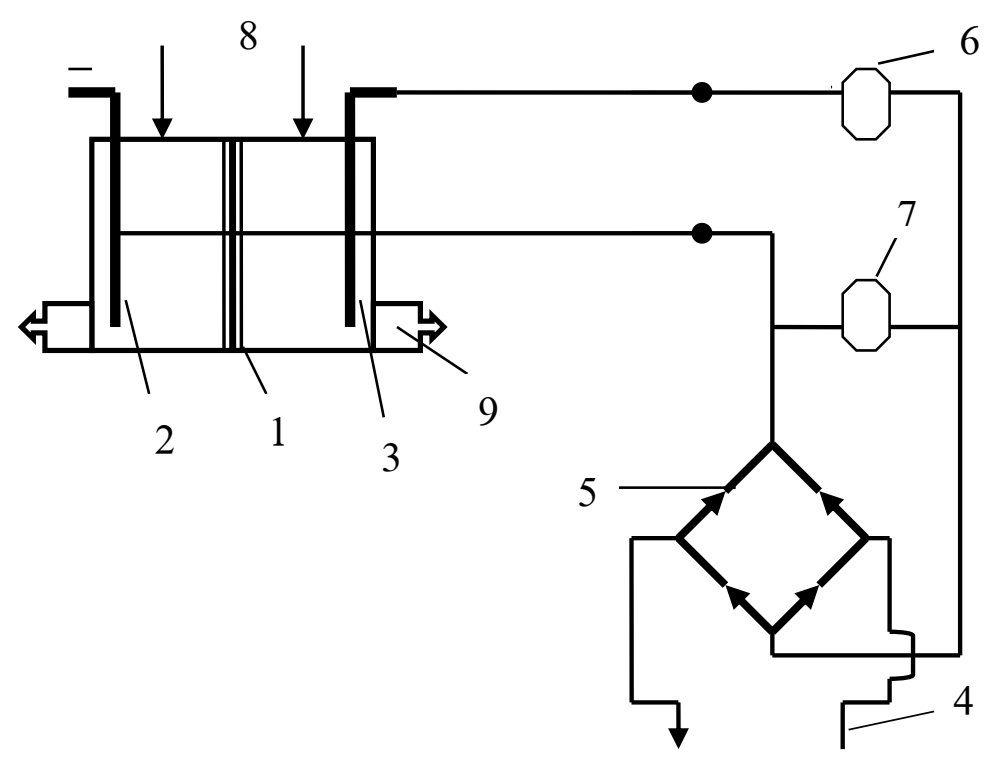

Fig. 1. Scheme of the laboratory installation of the electrodializer: 1 - membrane; 2 - cathode; 3 anode; 4 - rectifier; 5 - LATR-1M; 6 - ammeter; 7 - voltmeter; 8 - sewage; 9 - outlet pipes.

The electrodes were supplied with direct current from a rectifier (4) mounted on a bridge circuit made of diodes and connected to the AC network via LATR-1M (5). Current and voltage were measured using an ammeter (6) and a voltmeter (7) of class 0.5 . Wastewater (8) was fed in equal amounts to the cathode and anode zones of the electrodializer and electrodialysis was performed. At the end of the electrochemical process through the outlet pipes (9) purified water was simultaneously and in equal amounts drained from the cathode and anode zone of the installation.

Electrodialysis took place at an initial current of $0.2 \mathrm{~A}$, water temperature $293 \mathrm{~K}$, duration of action 5, 10, 15 and 20 minutes.

After electrodialysis, the composition of wastewater was studied by physicochemical and microbiological parameters.

\subsection{Determination of physicochemical and microbiological parameters}

The chloride content was determined by the method of [State Standard of Ukraine. DSTU ISO 9297: 2007 Water quality. Determination of chloride. Silver nitrate titration with chromate indicator (Mohr's method)], total nitrogen content [State Standard of Ukraine. DSTU ISO 5663: 2007 Water quality.

Determination of kjeldahl nitrogen. Method after mineralization with selenium (ISO 5663: 1984, IDT)], weighted substances [State Standard of Ukraine. DSTU EN 872: 2013 Water quality.

Determination of suspended solids method by filtration through glass fiber filters (EN 872: 2005, IDT)], calcined residue [State Standard. GOST18164-72 Drinking water. Method for determination of total solids content], sulfates [State Standard of Ukraine. GOST 31940-2012. Drinking water. Methods for determination of sulfate content (ISO 787-13-73 General methods of test for pigments and extenders. Determination of water- 
soluble sulphates, chlorides and nitrates)], chemical consumption of oxygen [State Standard of Ukraine. DSTU ISO 6060: 2003. Water quality. Determination of the chemical oxygen demand (ISO 6060: 1989, IDT)]. Water $\mathrm{pH}$ values were measured by potentiometric method [State Standard of Ukraine. DSTU 4077-2001. Water quality. Determination of pH (ISO10523: 1994, MOD)]. The total microbial count was determined by the method [ISO 6222: 1999 Water quality. Enumeration of culturable micro-organisms. Colony count by inoculation in a nutrient agar culture medium (ISO 6222: 1999)]

Laboratory tests were performed in triplicate. Statistical processing of the obtained results was performed using the MS Excel software package. The error of experimental researches was within the limits provided by research methods.

Mathematical models of optimization of parameters of process of clearing and disinfection of sewage by electrodialysis constructed by means of a package were used in work.

\section{Results}

As a result of the study, some conclusions were made regarding significant contamination of wastewater with organic and mineral substances. These findings were confirmed by laboratory studies (table 1 - 2).

Table 1. The composition of sewage 3 stages of yeast separation.

\begin{tabular}{|l|c|c|c|}
\hline \multicolumn{1}{|c|}{ Indicators } & $\begin{array}{c}\text { 1st degree } \\
\text { Sewage }\end{array}$ & $\begin{array}{c}\text { 2nd degree } \\
\text { Sewage }\end{array}$ & $\begin{array}{c}\text { 3rd degree } \\
\text { Sewage }\end{array}$ \\
\hline $\mathrm{pH}$ & 4.80 & 4.9 & 5.2 \\
\hline Chlorides, $\mathrm{mg} / \mathrm{dm}^{3}$ & 2147 & 1093 & 814 \\
\hline Nitrogen total, $\mathrm{mg} / \mathrm{dm}^{3}$ & 10.8 & 8.9 & 6.2 \\
\hline Suspended substances, $\mathrm{mg} / \mathrm{dm}^{3}$ & 6800 & 2000 & 800 \\
\hline Calcined residue, $\mathrm{mg} / \mathrm{dm}^{3}$ & 3600 & 800 & 400 \\
\hline Sulfates, $\mathrm{mg} / \mathrm{dm}^{3}$ & 6089 & 2798 & 1481 \\
\hline $\mathrm{COC}, \mathrm{mg} \mathrm{O} / \mathrm{dm}^{3}$ & 31096 & 15504 & 8120 \\
\hline $\mathrm{TMC}, \mathrm{CFU} \mathrm{cm} \mathrm{cm}^{3}$ & $12 \cdot 10^{7}$ & $21 \cdot 10^{6}$ & $12 \cdot 10^{6}$ \\
\hline
\end{tabular}

From the above results it is seen that the $\mathrm{pH}$ value in all studied samples of sewager indicates an acidic reaction of the environment, chlorides exceed the norm by $2.3-6.1 \%$, suspended solids - by $2.7-22.7 \%$, sulfates - by $3,7-15.2 \%$, COC - at $16.2-62.2 \%$. The total microbial count is thousands of times higher than the norm for discharge into sewage treatment plants (STP). The total nitrogen is within normal limits.

Table 2. The composition of the total sewage discharge.

\begin{tabular}{|l|c|c|}
\hline \multicolumn{1}{|c|}{ Indicators } & Actual value & Norm for reset in STP \\
\hline $\mathrm{pH}$ & 4.7 & $6.5-9.0$ \\
\hline Chlorides, $\mathrm{mg} / \mathrm{dm}^{3}$ & 1351 & 350 \\
\hline Nitrogen total, $\mathrm{mg} / \mathrm{dm}^{3}$ & 11.8 & 50 \\
\hline Suspended substances, $\mathrm{mg} / \mathrm{dm}^{3}$ & 3200 & 300 \\
\hline Calcined residue, $\mathrm{mg} / \mathrm{dm}^{3}$ & 1600 & it isn't determined \\
\hline Sulfates, $\mathrm{mg} / \mathrm{dm}^{3}$ & 3457 & 400 \\
\hline $\mathrm{COC}, \mathrm{mg} \mathrm{O} 2 / \mathrm{dm}^{3}$ & 18240 & 500 \\
\hline TMC, $\mathrm{CFU} \mathrm{cm}{ }^{3}$ & $12 \cdot 10^{6}$ & 100 \\
\hline
\end{tabular}


It was found that the content of chlorides in sewage of the total discharge exceeds the norm by 3.9 times, sulfates - by 8.6 times, COC - by 36.5 times, it is characterized by a high level of color, low $\mathrm{pH}$, a significant amount of suspended solids and microorganisms. Total nitrogen is within normal limits.

The indicators of the investigated wastewater in most parameters exceed the discharge rates in the STP, and their discharge is possible only if treated to the normative values.

The work is based on the task of creating an improved method of sewage treatment and disinfection, which would increase its efficiency and performance that includes water treatment in the anode and cathode chamber of the diaphragm electrodializer, anode and cathode chambers operate in non-flow mode.

Under the action of a direct electric current on the insoluble anode, the discharge of chlorine ions and water molecules takes place with the release of gaseous chlorine and oxygen, which, dissolving in water, oxidize bacterial contaminants. Due to the release of oxygen in the anolyte, hydrogen ions are formed. During the presence of water in the cathode chamber at the cathode, a discharge of water molecules takes place with the formation of hydrogen gas and hydroxyl ions, which accumulate in the catholyte.

The process of electrodialysis is influenced by such indicators as current, voltage, ambient temperature. The interelectrode distance is determined depending on the composition and velocity of the electrolyte. The concentration of hydrogen ions does not significantly affect the electrodialysis process. The output of chlorine in the current remains at the same level in the $\mathrm{pH}$ range from 5 to 10 . The speed of water at constant operating parameters of the cell (voltage, interelectrode distance, $\mathrm{NaCl}$ concentration, strength and current density) varies depending on the speed of the electrolyte.

The study results of 3 stages sewage composition of yeast separation after electrodialysis are shown in table 3.

Table 3. The study results of 3 stages sewage composition of yeast separation after electrodialysis.

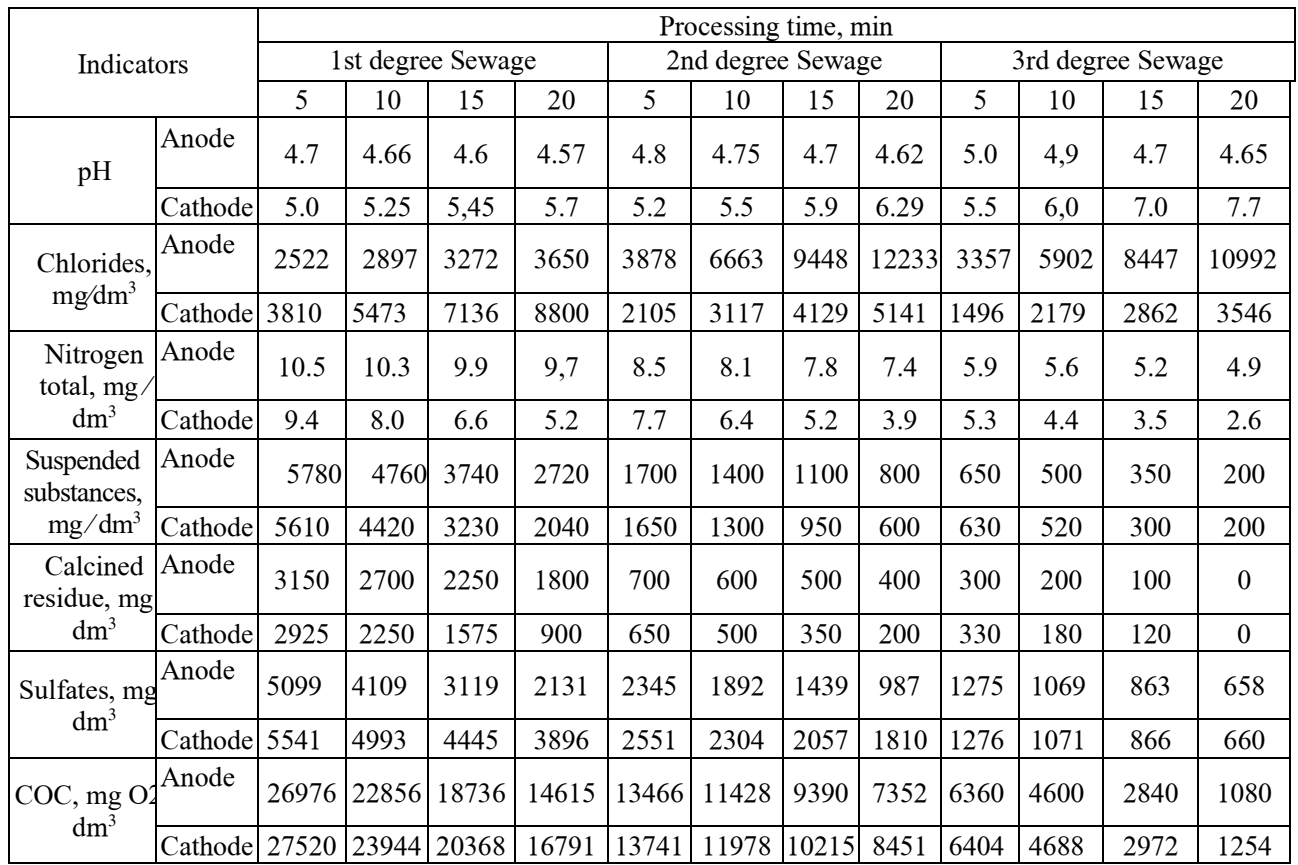


The duration of electrodialysis on the process of sewage treatment and disinfection at which the best results are achieved - 20 minutes.

For sewage of the 1st stage of yeast separation, such indicators as nitrogen, suspended solids, calcined residue, sulfates and COC are lower than the initial values by 10, 60, 50, 65 and $53 \%$, respectively, for the anode zone, and 52, 70, 75, 36 and $46 \%$ respectively for the cathode zone.

For sewage of the 2nd stage of yeast separation, such indicators as nitrogen, suspended solids, calcined residue, sulfates and COC are lower than the initial values by $17,60,50,65$ and $53 \%$, respectively, for the anode zone, and 56, 70, 75, 35 and $46 \%$ respectively for the cathode zone.

For sewage of the 3rd stage of yeast separation, such indicators as nitrogen, suspended solids, calcined residue, sulfates and COC are lower than the initial values by $21,75,100$, 56 and $87 \%$, respectively, for the anode zone, and 58,75, 100, 55 and $85 \%$ respectively for the cathode zone.

The study results of sewage composition of the total discharge after the action of electrodialysis are presented in table 4.

Table 4. Sewage physico-chemical composition of total discharge after electrodialysis.

\begin{tabular}{|c|c|c|c|c|c|}
\hline \multirow{2}{*}{\multicolumn{2}{|c|}{ Indicators }} & \multicolumn{4}{|c|}{ Processing time, $\min$} \\
\hline & & \multirow{2}{*}{$\frac{5}{4.65}$} & \multirow{2}{*}{$\begin{array}{c}10 \\
4.6 \\
\end{array}$} & \multirow{2}{*}{$\begin{array}{c}15 \\
4.55 \\
\end{array}$} & \multirow{2}{*}{$\begin{array}{l}20 \\
4.5\end{array}$} \\
\hline$n H$ & Anode & & & & \\
\hline pn & Cathode & 4.8 & 4.95 & 5.1 & 5.2 \\
\hline \multirow{2}{*}{ Chlorides, $\mathrm{mg} / \mathrm{dm}^{3}$} & Anode & 2786 & 4221 & 5656 & 7092 \\
\hline & Cathode & 1457 & 1563 & 1669 & 1773 \\
\hline \multirow{2}{*}{$\begin{array}{l}\text { Nitrogen total, } \mathrm{mg} \\
\mathrm{dm}^{3}\end{array}$} & Anode & 9.2 & 6.5 & 3,9 & 1,3 \\
\hline & Cathode & 9.3 & 6.7 & 4.2 & 1.6 \\
\hline \multirow{2}{*}{$\begin{array}{l}\text { Suspended } \\
\text { substances, } \\
\mathrm{mg} / \mathrm{dm}^{3}\end{array}$} & Anode & 2700 & 2200 & 1700 & 1200 \\
\hline & Cathode & 2750 & 2300 & 1850 & 1400 \\
\hline \multirow{2}{*}{$\begin{array}{l}\text { Calcined residue, mg, } \\
\mathrm{dm}^{3}\end{array}$} & Anode & 1402 & 1204 & 1006 & 810 \\
\hline & Cathode & 1296 & 992 & 688 & 385 \\
\hline \multirow{2}{*}{ Sulfates, $\mathrm{mg} / \mathrm{dm}^{3}$} & Anode & 3127 & 2798 & 2469 & 2139 \\
\hline & Cathode & 3086 & 2716 & 2346 & 1975 \\
\hline \multirow{2}{*}{$\mathrm{COC}, \mathrm{mg} \mathrm{O} 2 / \mathrm{dm}^{3}$} & Anode & 15966 & 13692 & 11418 & 9145 \\
\hline & Cathode & 16094 & 13948 & 11802 & 9654 \\
\hline
\end{tabular}

For general sewage, suspended solids, sulphates and COC are lower than similar control samples for the anode zone by $89,63,38$ and $50 \%$, respectively, and for the cathode zone by $86,56,43$ and $47 \%$, respectively.

In the anode chamber we obtain a new type of antimicrobial solution electrochemically activated anolyte. During the treatment of water in electroactivators (electric current), all molecular structures break down into ions. Water is saturated with highly active substances - oxidants and reducing agents. Under the action of electric current, as well as highly active oxidants and reducing agents, the destruction of microorganisms of all kinds and forms. The result is the death and decomposition of bacteria, spores, fungi, microorganisms into simple substances (namely water, carbon dioxide) [20].

Water disinfection is achieved through the following physicochemical processes:

- strong disinfecting action of a direct electric current. 
- chemical action on bacteria, viruses, zoo- and phytoplankton of strong oxidants, such as hydrogen peroxide, ozone, atomic oxygen, etc. Increasing the degree of disinfection is achieved by introducing metal chlorides $(\mathrm{KCl}, \mathrm{NaCl})$ into the water [21].

The process of sewage disinfection during electrodialysis depends on the content of $\mathrm{C} 1$ and SO42- ions. With increasing concentrations of chlorides in the treated water from 20 to $300 \mathrm{mg} / \mathrm{dm} 3$, the yield of chlorine in the current increases from 5 to $25 \%$. The presence of sulfates reduces the current output of chlorine by 4-5 times. This is due to the fact that SO42 ions, increasing the total electrical conductivity of the solution, do not participate in the formation of active chlorine [22].

The required dose of active chlorine is maintained by adjusting the amount of reagent supplied. During electrodialysis of treated water, the dose of chlorine can be regulated only electrically, for example by changing the amount of electricity consumed per $1 \mathrm{~m} 3$ of treated water. The output of chlorine in the current remains almost constant. Only the total amount of chlorine produced changes. The amount of chlorine in water increases in direct proportion to the energy expended. At chlorides concentration of $20-50 \mathrm{mg} / \mathrm{dm} 3$ it is economically expedient to use the method of direct electrodialysis at stations with a capacity of up to $800-1000 \mathrm{~m} 3 /$ day. At a higher content of chlorides in the water, electrodialysis disinfection can be used at water supply stations with a capacity of up to 3.55.0 thousand $\mathrm{m} 3 /$ day. Disinfection of se wage by electrodialysis should be carried out on facilities with a capacity of up to $500-1000 \mathrm{~m} 3$ / day [23].

The microbiological composition of sewage after electrodialysis is demostrated in table 5.

Table 5. The microbiological studies results of sewage before and after disinfection by electrodialysis.

\begin{tabular}{|c|c|c|c|c|c|c|c|c|c|c|c|c|c|}
\hline \multirow{3}{*}{\multicolumn{2}{|c|}{ 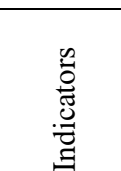 }} & \multicolumn{12}{|c|}{ Disinfection time, min. } \\
\hline & & \multicolumn{4}{|c|}{ 1st degree Sewage } & \multicolumn{4}{|c|}{ 2nd degree Sewage } & \multicolumn{4}{|c|}{ 3rd degree Sewage } \\
\hline & & 5 & 10 & 15 & 20 & 5 & 10 & 15 & 20 & 5 & 10 & 15 & 20 \\
\hline \multirow{2}{*}{ 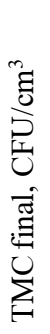 } & $\begin{array}{l}\frac{8}{0} \\
\frac{1}{2}\end{array}$ & 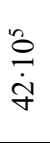 & 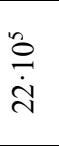 & $\begin{array}{l}n \\
\stackrel{0}{\infty} \\
\infty \\
0 \\
0\end{array}$ & 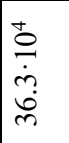 & $\begin{array}{l}\text { 号 } \\
\dot{\text { ஸे }}\end{array}$ & 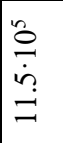 & 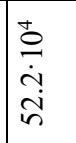 & $\begin{array}{l}\dot{0} \\
\dot{\sigma} \\
\dot{0}\end{array}$ & $\frac{n}{0}$ & $\frac{n}{0}$ & $\begin{array}{l}n \\
\stackrel{0}{0} \\
\dot{\dot{\sigma}} \\
\dot{n}\end{array}$ & 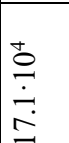 \\
\hline & 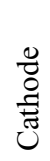 & $\begin{array}{l}\stackrel{\circ}{0} \\
\dot{\dot{d}} \\
\stackrel{\sim}{1}\end{array}$ & $\begin{array}{l}\stackrel{0}{0} \\
\dot{\infty} \\
\dot{\gamma} \\
\dot{\gamma}\end{array}$ & $\begin{array}{l}n \\
0 \\
\dot{6} \\
0 \\
0\end{array}$ & $\begin{array}{l}\stackrel{n}{0} \\
\stackrel{\dot{n}}{=} \\
=\end{array}$ & $\begin{array}{l}\stackrel{+}{0} \\
\stackrel{\dot{\Xi}}{\Xi}\end{array}$ & 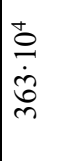 & 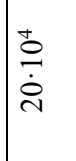 & $\begin{array}{l}\text { to } \\
\stackrel{0}{0} \\
\dot{0}\end{array}$ & $\begin{array}{l}\stackrel{8}{0} \\
\stackrel{\dot{m}}{-}\end{array}$ & 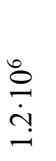 & $\frac{n}{\tilde{n}}$ & $\begin{array}{l}\text { ல } \\
\dot{\sim} \\
\text { ñ }\end{array}$ \\
\hline \multicolumn{2}{|c|}{ 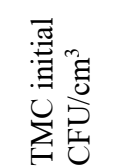 } & \multicolumn{4}{|c|}{$\begin{array}{l}\hat{0} \\
\dot{\mathfrak{c}}\end{array}$} & \multicolumn{4}{|c|}{$\begin{array}{l}\stackrel{\circ}{\vec{\tau}} \\
\dot{\vec{\lambda}}\end{array}$} & \multicolumn{4}{|c|}{ 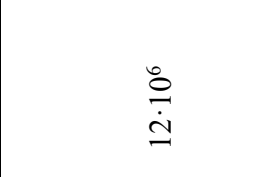 } \\
\hline
\end{tabular}

The table figure out that the total number of microorganisms after treatment of sewage by electrodialysis has decreased significantly compared to the initial values. The best process of sewage disinfection of yeast separation 3rd degree is observed in the anode zone, as evidenced by the degree of disinfection of $97.3-98.57 \%$. In sewage of the 1 st and 2 nd degree of separation, the reduction of TMC also occurs in the anode zone by 99.04 $99.69 \%$ and $96.76-97.05 \%$, respectively. 
The study results of sewage microbiological composition of the total discharge after the action of electrodialysis are shown in table 6 .

Table 6. Sewage microbiological composition of total discharge after electrodialysis.

\begin{tabular}{|c|c|c|c|c|c|}
\hline \multicolumn{2}{|c|}{ Indicators } & \multicolumn{4}{c|}{ Disinfection time, min. } \\
\cline { 3 - 6 } \multicolumn{2}{|c|}{} & 5 & 10 & 15 & 20 \\
\hline \multirow{2}{*}{$\begin{array}{c}\text { TMC final, } \\
\text { CFU } / \mathrm{cm}^{3}\end{array}$} & Anode & $6.1 \cdot 10^{5}$ & $5,9 \cdot 10^{5}$ & $5 \cdot 10^{5}$ & $82 \cdot 10^{4}$ \\
\cline { 2 - 6 } & Cathode & $1.4 \cdot 10^{6}$ & $1.3 \cdot 10^{6}$ & $8.9 \cdot 10^{5}$ & $88 \cdot 10^{4}$ \\
\hline \multicolumn{4}{|c|}{ TMC initial, CFU/cm ${ }^{3}$} & \multicolumn{5}{|c}{$12 \cdot 10^{6}$} \\
\hline
\end{tabular}

It was found that the best process of sewage disinfection took place in the anode zone with a duration of 20 minutes The degree of disinfection is $92.6-93.16 \%$.

Listed in table. 5, 6 numerical results demonstrate how the value of TMC varies depending on the time of electrodialysis $\tau$. We have assumed that this dependence is generally described by law

$$
\operatorname{TVC}(\tau)=\mathrm{TVC}_{0} \cdot \exp (\alpha+\beta \tau)
$$

where $\mathrm{TVC}_{0}$ is the value of the TMC at the initial time, and the change dynamics of the TMC does not depend on the type of wastewater studied, but depends only on where exactly - near the anode or cathode - the treatment took place. In other words, we assume that there are certain coefficients $\alpha^{(a)}, \beta^{(a)}$, which determine the dependence of $\operatorname{TVC}(\tau)$ in the anode zone, and the coefficients $\alpha^{(\mathrm{c})}, \beta^{(\mathrm{c})}$ respectively, for the cathode zone.

From the model we have chosen, it follows that

$$
\ln \left(\frac{\operatorname{TVC}(\tau)}{\operatorname{TVC}_{0}}\right)=\alpha+\beta \tau
$$

For each type of sewage, the value of the $\frac{\operatorname{TVC}\left(\tau_{i}\right)}{\mathrm{TVC}_{0}}$ ratio was calculated for individual moments of time on the basis of known TMC; they are shown in Fig. 2 on a logarithmic scale along the y-axis.

In order to find the coefficients $\alpha^{(a)}, \beta^{(a)}, \alpha^{(c)}, \beta^{(c)}$, two regression lines were constructed - the first approximates $n=16$ calculated for the anode zone values of $\ln \left(\frac{\operatorname{TVC}\left(\tau_{\mathrm{i}}\right)}{\mathrm{TVC}_{0}}\right)$ and the second also approximates $\mathrm{n}=16$ values, but calculated for the cathode zone. Measurement results were used for time points $\tau_{i}=5,10,15,20 \mathrm{~min}$, because during the first 5 minutes of the electrodialysis process the decrease in the value of SMC in both the anode and cathode zone is quite fast, and the time dependence deviates from the line constructed for $\tau>5 \mathrm{~min}$

For the coefficient $\alpha^{(c)}$ of the regression line, which corresponds to the data measured in the cathode zone, the values of $\alpha^{(\mathrm{c})}=-1.5$ and $95 \%$ confidence interval $[-2.5 ;-0.5]$, and for the coefficient $\beta^{(\mathrm{c})}$ the value of $\beta^{(\mathrm{c})}=-0.111$ and $95 \%$ confidence interval $[-0.183$; 0.039].

For the regression line constructed from the results of measurements in the anode zone, it turned out that the hypothesis of the difference between the coefficient $\beta^{(a)}$ (zero) can not be accepted with a confidence level of $95 \%$, because the value found $\beta^{(a)}=-0,0496$ satisfies the inequalities $\left|\beta^{(a)}\right| / \sqrt{D\left[\beta^{(a)}\right]}<t_{0,95 ; 14}=2.1452$, where $t_{0,95 ; 14}$ - a quantile of the level of 0.95 Studentas distribution with $n-2=14$ degrees of freedom. Therefore, the coefficient $\beta^{(c)}$, which characterizes the slope of the regression line, is not significant, and therefore for the approximation will have to be satisfied only with the coefficient $\alpha^{(a)}$, 
which is now calculated as the average of 16 measurement results in the anode zone. For the specified coefficient, the values of $\alpha^{(a)}=-3,6$ and $95 \%$ confidence interval were found $[-4.05 ;-3.13]$.

From the obtained numerical results we conclude that in the process of electrodialysis the index of the TMC near the cathode during the first 5 minutes decreases to the level $\frac{\operatorname{TVC}(\tau=5)}{\mathrm{TVC}_{0}}=\exp \left(\alpha^{(\mathrm{c})}+\beta^{(\mathrm{c})} \cdot 5\right)=0.13$, and during the next 15 minutes decreases in $\frac{\operatorname{TVC}(\tau=5)}{\operatorname{TVC}(\tau=15)}=\frac{\exp \left(\alpha^{(c)}+\beta^{(c)} \cdot 5\right)}{\exp \left(\alpha^{(c)}+\beta^{(c)} \cdot 15\right)} \approx 3$ times. On the other hand, near the anode, the TMC for the first 5 minutes falls to the level $\frac{\operatorname{TVC}(\tau=5)}{\operatorname{TVC}_{0}}=\exp \left(\alpha^{(a)}\right)=0.028$ from the initial value. Further changes in the TMC in the anode zone are not observed to the accuracy of the errors in the measurement of the TMC (Figure 2).

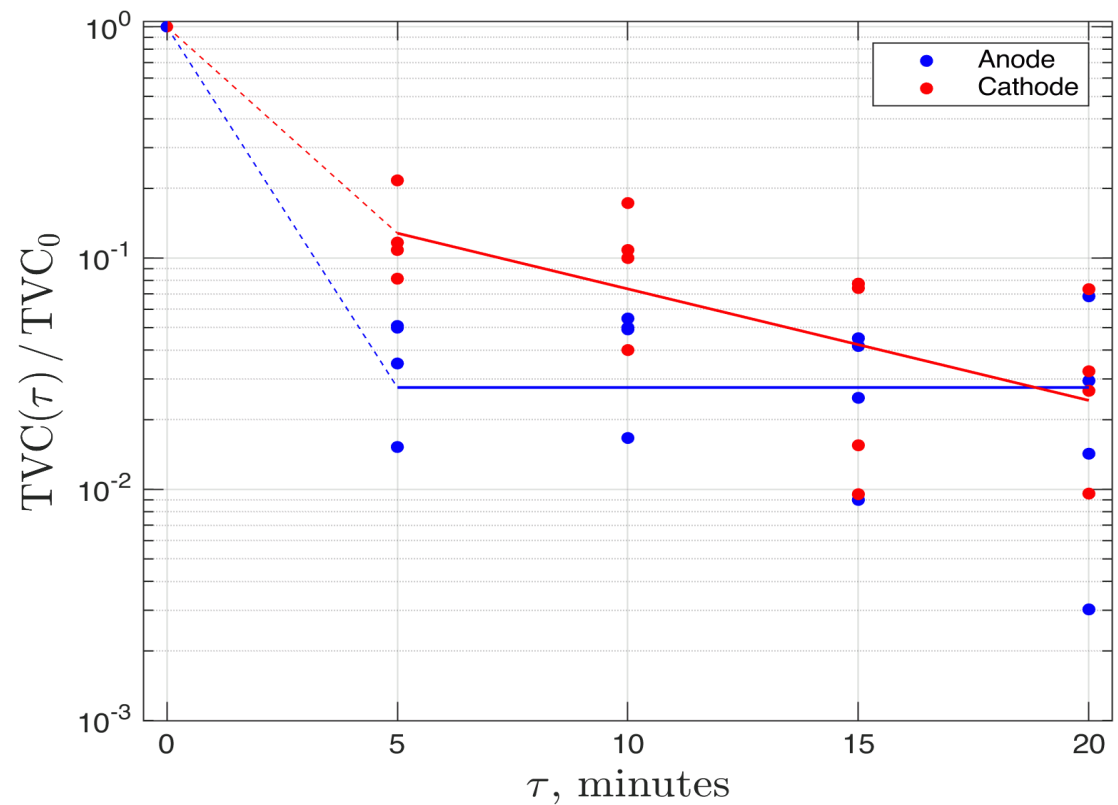

Fig. 2. Approximation of the duration effect dependence of electrodialysis treatment $(\tau)$ on the TMC of total discharge and sewage of 1-st, 2-nd, 3rd stages of yeast separation.

\section{Discussion}

In the interval of processing duration of $15-20 \mathrm{~min}$. the lowest indicator of TMC is reached. The highest degree of sewage disinfection is observed in the anode zone due to the accumulation during electrodialysis in the anode zone of chloride ions and atomic oxygen, which contribute to the oxidation of organic matter and the death of microorganisms.

As the duration of electrodialysis increased, as expected, the TMC of all investigated sewage decreased. The decrease was quite large: with a duration of exposure of $20 \mathrm{~min}$. TMC decreased by $92-99 \%$. The decrease was almost linear with the duration of action in the considered range. This dependence suggests that the limit of reducing the content of microorganisms has not yet been exhausted, and perhaps even more reduction in the number of microorganisms, which can be provided by a longer exposure to the electric field. [24] 
The effect of disinfection during electrodialysis of water depends on the amount of electricity consumed, the residence time of water in the installation.

With increasing amount of electricity per $1 \mathrm{dm} 3$ of treated water, the degree of water purification increases. However, in all cases with any minimal infection, the desired effect of disinfection is observed only at a certain amount of residual chlorine. With increasing water pollution, the concentration of chlorine required for its complete disinfection increases. If this condition is not met, then regardless of the amount of electricity applied, complete disinfection of water is not achieved.

The state of the aqueous medium (temperature, $\mathrm{pH}$, turbidity and color) significantly affects the efficiency of the disinfection process in the electrodializer.

With increasing concentration of chlorine in water, increasing its temperature, the speed of the disinfection process increases. The adverse effects of low temperatures can be offset by increasing the dose of chlorine and prolonging the time of its contact with the treated water.

The bactericidal effect of chlorine is enhanced by lowering the $\mathrm{pH}$ of the medium. As the $\mathrm{pH}$ decreases, the dissociation degree of hydrochloric acid formed during the hydrolysis of chlorine in water decreases, and, consequently, a large concentration of more active substance (HOC1) remains in the water and the concentration of less active hypochlorite ion $\mathrm{OC} 1$ decreases accordingly.

Hypochlorites, hypochlorous acid and molecular chlorine readily react with ammonia present in water, ammonium or organic salts containing amino groups, forming mono- and dichloramines, nitrogen chloride. During the hydrolysis of the obtained compounds, active chlorine is released, so they also have a bactericidal effect [25].

\section{Conclusions}

Physicochemical and microbiological indicators of sewage composition after 1, 2 and 3 stages of yeast separation and total discharge, which contain a large number of organic substances and microorganisms, have been experimentally determined.

The parameters of electrodialysis action on sewage treatment and disinfection are optimized. For sewage of the 1st stage of yeast separation, the treatment duration is 20 minutes, the current value is $0.4-0.2 \mathrm{~A}$, the voltage is $19-20 \mathrm{~V}$, the ambient temperature is $293 \mathrm{~K}$, with nitrogen, suspended solids, calcined residue, sulfates and COCs are lower than the initial values by $10,60,50,65$ and $53 \%$, respectively, for the anode zone, and 52 , $70,75,36$ and $46 \%$, respectively, for the cathode zone. The degree of disinfection is $99.04-$ $99.69 \%$.

For wastewater of the 2nd stage of yeast separation, the treatment duration is 20 minutes, the current value is $0.5-0.2 \mathrm{~A}$, the voltage is $18-19 \mathrm{~V}$, the medium temperature is $293 \mathrm{~K}$, with nitrogen, suspended solids, calcined residue, sulfates and COCs are lower than the initial values by $17,60,50,65$ and $53 \%$, respectively, for the anode zone, and 56 , $70,75,35$ and $46 \%$, respectively, for the cathode zone. The degree of disinfection is $96.76-$ $97.05 \%$.

For wastewater of the 3rd stage of yeast separation, the treatment duration is 20 minutes, the current value is $0.5-0.2 \mathrm{~A}$, the voltage is $15-16 \mathrm{~V}$, the medium temperature is $293 \mathrm{~K}$, with nitrogen, suspended solids, calcined residue, sulfates and COCs are lower than the initial values by $21,75,100,56$ and $87 \%$, respectively, for the anode zone, and 58 , $75,100,55$ and $85 \%$, respectively, for the cathode zone. The degree of disinfection is 97.3 $98.57 \%$.

For sewage of total discharge, the treatment duration is 20 minutes, current value 0.5 $0.2 \mathrm{~A}$, voltage $18-19 \mathrm{~V}$, ambient temperature $293 \mathrm{~K}$, with suspended solids, sulfates and COC below similar indicators of control samples for the anode zone by $89,63,38$ and $50 \%$ 
respectively, and for the cathode zone by $86,56,43$ and $47 \%$ respectively. The degree of disinfection is $92.6-93.16 \%$.

\section{References}

1. N.V. Mailunets, M.M. Zatserklyanny, Water consumption and promising equipment for wastewater treatment. Collection of abstracts of the X All-Ukrainian scientificpractical conference of young scientists, graduate students and student (Odessa) (2019)

2. O.O. Emonakova, Improvement of wastewater treatment technologies after grain soaking Collection of abstracts of the $X$ All-Ukrainian scientific-practical conference of young scientists, graduate students and student (Odessa) (2019)

3. A.T. Bezusov, N.V. Dotsenko, Biotechnological processing of industrial effluents Collection of abstracts of the X All-Ukrainian scientific-practical conference of young scientists, graduate students and student (Odessa) (2019)

4. V.P. Kovalsky, V.P. Ocheretny, M.O. Postolatiy, Promising technologies, modern reagents and materials for wastewater treatment Collection of abstracts of the $X$ AllUkrainian scientific-practical conference of young scientists, graduate students and student (Odessa) (2019)

5. R.V. Mnykh, Y.V. Sukhatsky, O.I. Zin, Cavitation wastewater treatment of meat processing enterprises Collection of abstracts of the $X$ All-Ukrainian scientificpractical conference of young scientists, graduate students and students (Odessa) (2019)

6. G.O. Bilyavsky, L.I. Butchenko, Fundamentals of ecology Textbook (2002)

7. D.I. Kibirev, K.S. Pozhivilko, G.I. Nikiforov, A method of treating water with sodium hypochlorite and a flow cell to obtain sodium hypochlorite RF patent 2100483 (1997)

8. B.C. Brazhkin, N.P. Kuprikov O.A. Zhuravkov, Method of electrochemical treatment of water with disinfectants RF patent 2500625 (2013)

9. V.V. Kunizhenkov, M.S. Yaroshinskiy, Y.P. Struk, L.Z. Boguslavskiy Y.G. Kazaryan, Installation for water contamination Patent of Ukraine 99276 Bull 3 (1997)

10. L.Z. Boguslavsky, Y.G. Ghazaryan, J.P. Struk, V.V. Kunizhenkov, M.S. Yaroshinsky, Installation for water disinfection Patent of Ukraine 99276 Bull 10 (2015)

11. D.I. Kibirev, K.S. Pozhivilko, G.I. Nikiforov, A method of treating water with sodium hypochlorite and a flow cell to obtain sodium hypochlorite RF patent 2100483 (1997)

12. B.C. Brazhkin, N.P. Kuprikov, O.A. Zhuravkov, Method of electrochemical treatment of water with disinfectants RF patent 2500625 (2013)

13. L.V. Filipchuk, V.L. Filipchuk, Method of electrochemical disinfection of water Patent of Ukraine 111278 Bull 21 (2016)

14. I.A. Burtna, D.V. Litvinenko, Review of membrane technologies of water purification in water supply and water treatment, East European Journal of Advanced Technologies 6/10 (60), 4-6, 1729-3774 (2012)

15. D.I. Kibirev, K.S. Pozhivilko, G.I. Nikiforov, Published A method of treating water with sodium hypochlorite and a flow cell to obtain sodium hypochlorite RF patent 2100483 (1997)

16. B.C. Brazhkin, N.P. Kuprikov, O.A. Zhuravkov, Method of electrochemical treatment of water with disinfectants RF patent 2500625 (2013) 
17. S.G. Chulkov, A.O. Mokin, P.S. Latukhin, G.V. Styr, O.M. Plitkin, L.D. Barkov, Method of water purification and disinfection Patent of Ukraine 106611 Bull 8 (2016)

18. B.C. Brazhkin, N.P. Kuprikov, O.A. Zhuravkov, Method of electrochemical treatment of water with disinfectants RF patent 2500625 (2013)

19. A.A. Kulakov, Features of purification of tap water by means of electrodialysis (2019) (Electronic Materials) URL https://watermagazine.ru/nauchnye-stati2/novyestati/23021-osobennosti-ochistki-vodoprovodnoj-vody-s-pomoshchyu-

elektrodializa.html

20. V.D. Kurtov, On the amazing properties of electroactivated water (2007)

21. N.M. Romanchenko, V.B. Kostin, Reagent-free method of water disinfection by electroactivation Prospects for the future and realities of the present in water treatment technologies: Proceedings of the III International Scientific and Practical Conference (Kyiv) (2019)

22. O.V. Goltvyanytska, T.O. Shabliy, M.D. Gomel, S.S. Stavska, Removal and separation of chlorides and sulfates during ion exchange desalination of water, Eastern European Journal of Advanced Technologies 1/6 (55), 40-44 (2012)

23. A.A. Kulakov, Peculiarities of tap water purification by means of electrodialysis Journal "Water Magazine" was published by LLC "ID" EcoMedia (2018) URL: https://watermagazine.ru/zhurnal/informatsiya.html

24. A.A. Kulakov, Features of purification of tap water by means of electrodialysis (2019) URL: https://watermagazine.ru/nauchnye-stati2/novye-stati/23021-osobennostiochistki-vodoprovodnoj-vody-s-pomoshchyu-elektrodializa.html

25. O.A. Squeezed, V.G. Petruk, Analysis of factors of ecological danger of chlorinated drinking water, Bulletin of Vinnytsia Polytechnic Institute 5, 69-75, 1997-9266 (2014) 